\title{
ANALISIS FAKTOR-FAKTOR YANG MEMPENGARUHI PRODUKSI DAN PENDAPATAN PETANI KARET (STUDI KASUS PETANI KARET DI WILAYAH OPERASIONAL PERUSAHAAN MIGAS KABUPATEN MUSI BANYUASIN)
}

\author{
Analysis of Factors Affecting Rubber Production And Rubber Farmers Income \\ (Case Study of Rubber Farmers in the Musi Banyuasin Regency \\ Oil and Gas Operational Area) \\ Iman Satra NUGRAHA*, Aprizal ALAMSYAH dan Dwi Shinta AGUSTINA \\ Balai Penelitian Sembawa, Pusat Penelitian Karet \\ Jalan Raya Palembang-Pangkalan Balai KM 29 \\ Kotak Pos 1127 Palembang 30001, Sumatera Selatan \\ *Email : iman_satra@yahoo.com
}

Diterima : 12 Desember 2018 / Disetujui : 27 Desember 2018

\begin{abstract}
Musi Banyuasin is one of the districts that contributes to rubber production in South Sumatra Province. But on the other hand rubber production produced by rubber farmers is not optimal. Therefore this study aims to analyze the factors that influence rubber production so that the rubber production of farmers could be increased. Sampling was done purposively in 7 villages with each village consisting of 30 respondents. The data used are primary and secondary data and for data analysis using SPSS 16. Based on the results of the study, the education level of the majority farmers was only Elementary School and has rubber farming experience for 15 years. While the factors that significantly influence rubber production are the ownership of rubber $\left(X_{2}\right)$, number of labor $\left(X_{3}\right)$, type of planting material $\left(X_{4}\right)$ and use of fertilizer $\left(X_{5}\right)$. Whereas family income of IDR 3,732,000 per month and rubber is the largest source of earnings for total family income with a contribution of IDR 2,024,000 per month while the rest comes from trade and labor activities.
\end{abstract}

Keywords: rubber production, factors, rubber farmer

\section{Abstrak}

Musi Banyuasin merupakan salah satu kabupaten yang berkontribusi terhadap produksi karet di Provinsi Sumatera Selatan. Namun disisi lain produksi karet yang dihasilkan oleh petani karet belum optimal. Oleh karena itu penelitian ini bertujuan untuk menganalisis faktor yang mempengaruhi produksi karet sehingga produksi karet petani dapat meningkat. Pengambilan sampel dilakukan secara purposif di 7 desa dengan masingmasing desa terdiri 30 responden. Data yang digunakan adalah data primer dan sekunder dan untuk analisis data menggunakan SPSS 16. Berdasarkan hasil penelitian tingkat pendidikan petani mayoritas hanya mencapai Sekolah Dasar dan memiliki pengalaman berkebun karet selama 15 tahun. Sedangkan faktor yang berpengaruh nyata terhadap produksi karet adalah kepemilikan lahan karet $\left(\mathrm{X}_{2}\right)$, jumlah tenaga kerja $\left(\mathrm{X}_{3}\right)$, jenis bahan tanam yang digunakan $\left(\mathrm{X}_{4}\right)$ dan penggunaan pupuk $\left(\mathrm{X}_{5}\right)$. Sedangkan pendapatan keluarga sebesar IDR 3.732.000,- per bulan dan karet merupakan sumber pendapatan terbesar terhadap total pendapatan keluarga dengan kontribusi sebesar IDR 2.024.000,- per bulan sedangkan selebihnya berasal dari kegiatan berdagang dan buruh.

Kata Kunci : Produksi karet, faktor-faktor, petani karet

\section{PENDAHULUAN}

Karet merupakan salah satu komoditas unggulan di provinsi Sumatera Selatan (Sumsel) selain kelapa sawit. Luas areal perkebunan karet di Sumatera Selatan 
pada tahun 2016 adalah 838.749 Ha. Luasan tersebut terdiri dari perkebunan rakyat 791.187 Ha (94\%), perkebunan negara $11.334 \mathrm{Ha}(2 \%)$ dan perkebunan swasta 36.228 Ha (4\%). Perkebunan karet berkontribusi terhadap penyerapan tenaga kerja yaitu sebanyak $463.568 \mathrm{KK}$ terlibat dalam usaha perkebunan karet (Direktorat Jenderal Perkebunan, 2016). Selain itu, menjadi penyumbang devisa Negara peringkat ke 9 dengan kontribusi sebesar 65 triliun pada tahun 2017 (Antariksa, 2017). Permasalahan yang masih dihadapi hingga saat ini adalah mengenai produktivitas perkebunan Sumsel yang masih rendah karena sampai tahun 2012 penggunaan bibit klonal hanya mencapai 59,2 \% (Boerhendhy \& Amypalupy, 2011; Syarifa,et al., 2012). Peningkatan kesadaran untuk menggunakan bibit unggul sangat diperlukan untuk dapat meningkatkan produktivitas karet.

Kabupaten Musi Banyuasin memiliki areal perkebunan karet terbesar di Sumsel yaitu seluas 132.524 Ha(Direktorat Jenderal Perkebunan, 2016) sehingga komoditas tersebut menjadi sumber pendapatan utama bagi masyarakat Musi Banyuasin (Hafsah, et al., 2014). Selain perkebunan karet, Kabupaten Musi Banyuasin juga memiliki perusahaan non pertanian seperti migas. Keberadaan perusahaan migas tidak secara langsung dapat meningkatkan pendapatan petani. Pendapatan petani akan meningkat jika diikuti oleh peningkatan produksi karet dan peningkatan karet (Siburian, 2012; Stiawan, et al., 2014; Sudjarmoko, et al., 2013). Jika harga karet tidak stabil maka pendapatan petani karet juga menjadi tidak stabil (Pasaribu, 2017). Selain harga karet, jumlah produksi karet ditingkat petani juga dapat mempengaruhi pendapatan petani. Jumlah produksi ini akan berkorelasi dengan tingkat produktivitas kebun karet rakyat. Pada umumnya petani masih menggunakan tanaman karet alam sehingga produktivitas tanaman karetnya sangat rendah (Boerhendhy, 2011; Hadi, 2010; Sagala, et al., 1997; Saptabina Usatani Karet Rakyat, 2012). Rendahnya produktivitas disebabkan rendahnya tingkat adopsi klon unggul (Syarifa, Agustina, Alamsyah, \& Nugraha, 2017). Untuk meningkatkan adopsi klon unggul dapat dilakukan oleh pemerintah maupun swasta melalui program pemberdayaan masyarakat maupun swadaya petani karet. Oleh karena itu penulis mengangkat faktor-faktor yang dapat mempengaruhi produksi karet rakyat di areal operasional perusahaan migas. Melalui tulisan ini diharapkan dapat memberikan informasi kepada pembuat kebijakan bahwa jika ingin melakukan pemberdayaan masyarakat khususnya petani karet lebih memperhatikan faktor yang dapat meningkatkan produksi karet sehingga akan berdampak kepada peningkatan produksi karet dan akan dapat meningkatkan pendapatan petani karet.

\section{BAHAN DAN METODE}

\section{Pengumpulan Data}

Penelitian dilakukan pada tahun 2016 dan 2017 dengan menggunakan responden sebanyak 210 orang. Pemilihan responden dilakukan secara sengaja yaitu dengan mempertimbangkan petani karet yang berada di dekat operasional perusahaan. Lokasi penelitian dilakukan di 7 desa yaitu Desa Macang Sakti, Lubuk Bintialo, Pangkalan Bulian, Tampang Baru, Sukamaju, Letang dan Supat. Masingmasing desa terdiri dari 30 responden. Data yang digunakan adalah data primer dan sekunder. Data primer diperoleh dengan menggunakan wawancara terstruktur dengan menggunakan kuisioner. Sedangkan data sekunder diperoleh dari studi literatur (LIPI, 2014b) seperti data luasan kebun karet dan kultur teknis budidaya karet.

\section{Analisis Data}

Pengolahan data dilakukan secara kualitatif dan kuantitatif. Analisis kualitatif dilakukan secara deskriptif sedangkan analisis kuantitatif menggunakan alat analisis microsoft excel dan SPSS 16. Fungsi produksi menunjukkan jumlah maksimum output yang dapat dihasilkan dari pemakaian sejumlah input dengan menggunakan teknologi tertentu. Faktorfaktor produksi dikenal dengan istilah input dan jumlah produksi disebut output. Secara matematika fungsi produksi selalu dinyatakan dalam bentuk rumus seperti berikut: 
Analisis Faktor-Faktor yang Mempengaruhi Produksi dan Pendapatan Petani Karet (Studi Kasus Petani Karet di Wilayah Operasional Perusahaan Migas Kabupaten Musi Banyuasin)

$$
Q=f(K, L, X, E)
$$

Dimana :

$\mathrm{K}=$ Jumlah stok modal/ capital

$\mathrm{L}=$ Jumlah tenaga kerja dan ini meliputi berbagai jenis tenga kerja

$\mathrm{X}=$ kekayaan alam/ bahan baku

$\mathrm{E}=$ Tingkat teknologi yang digunakan/ keahlian keusahawan

$\mathrm{Q}=$ jumlah produksi (output)

Jadi kapasitas produksi dalam perekonomian (Q) akan dipengaruhi oleh besarnya K,L,X, dan E. Fungsi produksi menentukan kemungkinan output maksimal yang mungkin diproduksi dengan jumlah input tertentu atau sebaliknya. Sedangkan untuk mengetahui faktor-faktor yang mempengaruhi produksi karet rakyat menggunakan program SPSS 16. Variabel yang diduga dapat mempengaruhi produksi ada 6 variabel. Pemilihan variabel tersebut dilakukan berdasarkan pengamatan di lapangan dan penelitian terdahulu (Diantoro, et al., 2009; Firdaus \& Huda, 2015; Septianita, 2009). Variabel yang diduga berpengaruh terhadap produksi yaitu :

$\mathrm{X}_{1}$ : Umur tanaman karet (th)

$\mathrm{X}_{2}$ : Kepemilikan lahan karet (ha)

$\mathrm{X}_{3}$ : Tenaga kerja (HK)

$\mathrm{X}_{4}$ : Dummy jenis bahan tanam yang digunakan $(1=$ jika menggunakan bibit klonal dan 0 = jika menggunakan bibit seedling)

$\mathrm{X}_{5}$ : Pupuk (kg per tahun)

$\mathrm{X}_{6}$ : Jumlah hari sadap per tahun

Y : Produksi karet (kg per tahun)

Untuk mendapatkan model yang baik maka variabel tersebut harus bebas dari sifat multikolinieritas dan autokorelasi. Cara pengujian hipotesis ada tidaknya multikolinearitas pada model regresi adalah jika nilai VIF $>$ nilai Tolerance atau VIF $<10$ maka Tolak $\mathrm{H}_{0}$ berarti model regresi tersebut tidak mengandung multikolinieritas sedangkan nilai VIF < nilai Tolerance atau nilai VIF > 10 maka terima $\mathrm{H}_{0}$ yang berarti ada multikolinieritas. Uji autokorelasi adalah korelasi antar anggota serangkaian observasi yang diurutkan menurut waktu dan ruang. Cara pengujian autokorelasi yaitu dengan uji Durbin-watson dengan hipotesis sebagai berikut:

a) $\mathrm{H}_{0}$ : ada autokorelasi dengan syarat $\mathrm{dW}$ hitung < dU (batas atas) b) $\mathrm{H}_{1}$ : tidak ada autokorelasi dengan syarat $\mathrm{dW}$-hitung > dU (batas atas).

Setelah variabel telah terbebas dari sifat tersebut maka perlu dilakukan pengujian parameter model dan parameter variabel (Nazir, 2005). Pengujian parameter model (Uji F) bertujuan untuk melihat apakah variabel bebas (independent) yang digunakan secara bersama-sama berpengaruh nyata pada variabel tak bebas (dependent) (Sudrajat, 1985). Uji statistik yang digunakan adalah uji F. Pengujian parameter variabel (Uji t) bertujuan untuk mengetahui apakah koefisien regresi dari masing-masing variabel independent (X) yang digunakan berpengaruh signifikan terhadap variabel dependent (Y)(LIPI, 2014a). Uji statistik yang digunakan adalah uji t dan taraf nyata digunakan adalah $\mathrm{a}=10 \%$.

\section{HASIL DAN PEMBAHASAN}

\section{Karakterisasi Petani Karet}

Petani responden berasal dari wilayah operasional perusahan migas di Kabupaten Musi Banyuasin. Meskipun petani tersebut berada di areal operasional perusahaan migas, berkebun karet merupakan salah satu pilihan petani untuk menopang perekonomian keluarga. Berkebun karet terus dilakukan karena sudah menjadi usaha turun - temurun.

Berdasarkan data responden yang dikumpulkan, diketahui bahwa petani karet pada umumnya memiliki tingkat pendidikan Sekolah Dasar (SD). Hal tersebut dapat dilihat pada Tabel 1 yang menunjukkan bahwa $55 \%$ petani berpendidikan SD, bahkan 3\% petani Buta Huruf $(\mathrm{BH})$. Petani yang mencapai jenjang perguruan tinggi hanya sebesar 1\%, hal tersebut dikarenakan responden yang memiliki jenjang pendidikan yang tinggi tidak lagi menjadikan berkebun karet menjadi usaha utama dan lebih memilih sektor perkantoran. Sedangkan jika dilihat dari sebaran umur, pada umumnya petani karet masih berada pada kategori usia produktif yaitu usia 26 - 35 tahun sebesar 26\%, usia 36 - 45 tahun sebesar $29 \%$, usia 46 - 55 tahun sebear 24\%, dan sisanya adalah dibawah 25 tahun 4\% serta diatas 56 tahun sebesar 17\%. Sebaran umur yang produktif akan mendorong petani karet 
lebih produktif untuk meningkatkan hasil perkebunan karet dan kebun dapat lebih terpelihara (Harwati, et al., 2015). Salah satu bukti bahwa berkebun karet merupakan usaha yang turun -temurun adalah dengan usia petani karet yang tergolong muda namun pengalaman responden dalam menekuni berkebun karet cukup lama yaitu rata-rata petani memiliki pengalaman berkebun karet selama 15 tahun. Dengan demikian bahwa petani karet sudah diperkenalkan dan ikut terlibat langsung pada usahatani karet sejak dari remaja. Profil responden ditampilkan pada Tabel 1.

\section{Faktor-Faktor Yang Mempengaruhi Produksi Karet}

Faktor-faktor produksi yang berpengaruh terhadap jumlah produksi karet di wilayah operasional migas, berdasarkan hasil regresi dapat diformulasikan sebagai berikut:

$\mathrm{Y}=-79,4 \mathrm{X}_{1}+7100 \mathrm{X}_{2}+20 \mathrm{X}_{3}-155,8 \mathrm{X}_{4}+7 \mathrm{X}_{5}-$ $19,5 \mathrm{X}_{6}-10.932$

Pengujian model regresi dengan asumsi klasik berdasarkan hasil uji multikolinieritas, hasil pengujian koefisiensi regresi fungsi menunjukkan bahwa nilai Value Inflaction Factor (VIF) untuk semua faktor produksi adalah kurang dari 10, maka dengan demikian hasil dari model koefisiensi fungsi regresi tidak mengandung gejala multikolinieritas (Tabel 4). Dari hasil pengujian menunjukkan nilai durbin Watson (dW) hitung sebesar 1,56. Nilai ini berada diantara 1,55 dan 2,46 sedangkan durbin Watson batas atas (dU) tabel sebesar 2,2026 hal ini menunjukkan bahwa dW > dU artinya tidak ada gejala autokorelasi pada persamaan regresi (Tabel 2).

Tabel 1. Profil petani karet responden

Table 1. Profile of rubber farmers respondent

\begin{tabular}{|c|c|c|c|}
\hline $\begin{array}{l}\text { No } \\
\text { No }\end{array}$ & $\begin{array}{c}\text { Uraian } \\
\text { Descriptions }\end{array}$ & $\begin{array}{l}\text { Kategori } \\
\text { Category }\end{array}$ & $\begin{array}{c}\text { Persentase } \\
\text { Percentage } \\
\text { (\%) }\end{array}$ \\
\hline \multirow[t]{5}{*}{1} & Pendidikan & $\mathrm{BH}$ & 3 \\
\hline & & $\mathrm{SD}$ & 55 \\
\hline & & SLTP & 22 \\
\hline & & SMA & 19 \\
\hline & & Perguruan Tinggi & 1 \\
\hline \multirow[t]{6}{*}{2} & Umur & $<25$ & 4 \\
\hline & & $26-35$ & 26 \\
\hline & & $36-45$ & 29 \\
\hline & & $46-55$ & 24 \\
\hline & & $56-65$ & 14 \\
\hline & & $>66$ & 3 \\
\hline \multirow[t]{3}{*}{3} & Pengalaman berkebun & $0-10$ & 43 \\
\hline & karet & $11-20$ & 36 \\
\hline & & $>21$ & 21 \\
\hline
\end{tabular}

Tabel 2. Hasil adjusted $\mathrm{r}$ square pada model regresi analisis faktor yang mempengaruhi hasil produksi karet.

Table 2. Adjusted r square results on regression analysis of factors affecting rubber production

\begin{tabular}{crrrrr}
\hline \multirow{2}{*}{ Model } & $\mathrm{R}$ & \multirow{2}{*}{ R Square } & $\begin{array}{c}\text { Adjusted R } \\
\text { Square }\end{array}$ & $\begin{array}{c}\text { Std. Error of the } \\
\text { Estimate }\end{array}$ & Durbin-Watson \\
\hline 1 &, $742^{\mathrm{a}}$ &, 551 &, 537 & 42314,15149 & 1,568 \\
\hline
\end{tabular}


Tabel 2 menunjukkan bahwa nilai koefisien determinasi dari persamaan regresi sebesar 0,537, yang berarti bahwa sebanyak $53,7 \%$ perubahan produksi karet dapat dijelaskan oleh faktor umur tanaman, luasan kebun, tenaga kerja, penggunaan bibit (unggul atau seedling), penggunaan pupuk, dan jumlah hari sadap. Sisanya sebesar 46,3\% dijelaskan oleh faktor lain yang tidak dimasukkan dalam variabel penelitian.

Pengujian kesesuaian model digunakan untuk menjawab hipotesis yang diajukan dalam penelitian ini dapat mencapai tujuan penelitian dan dapat dipertanggungjawabkan secara empiris. Hasil uji F pada model regresi dapat dilihat pada Tabel 3.

Berdasarkan hasil analisis regresi diperoleh nilai $\mathrm{F}$ hitung sebesar 40,642 > dari nilai $F$ tabel sebesar 2,34 dan nilai probabilitas signifikan sebesar 0,000 yang lebih kecil dari nilai alpha sebesar 0,10 maka dapat disimpulkan tolak $\mathrm{H}_{0}$, yang mempunyai arti bahwa faktor produksi umur tanaman karet $\left(\mathrm{X}_{1}\right)$, kepemilikan lahan karet $\left(\mathrm{X}_{2}\right)$, tenaga kerja $\left(\mathrm{X}_{3}\right)$, dummy jenis bahan tanam yang digunakan $\left(\mathrm{X}_{4}\right)$, jumlah penggunaan pupuk $\left(\mathrm{X}_{5}\right)$, jumlah hari sadap
$\left(\mathrm{X}_{6}\right)$ secara bersama-sama atau simultan berpengaruh signifikan terhadap jumlah produksi karet $(\mathrm{Y})$. Hasil ini sejalan dengan penelitian yang dilakukan oleh Fitriani, Abidin, \& Ibnu, (2013); Setyawan, Subantoro, \& Prabowo, (2016) yang menyatakan berdasarkan hasil penelitian yang telah dilakukan diketahui bahwa produksi karet dipengaruhi oleh luas panen dan penggunaan pupuk.

Berdasarkan hasil analisis regresi berganda menunjukkan ada 4 faktor produksi yang memiliki hubungan paling kuat terhadap jumlah produksi karet yaitu kepemilikan lahan karet $\left(\mathrm{X}_{2}\right)$, tenaga kerja $\left(\mathrm{X}_{3}\right)$, jenis bahan tanam yang digunakan $\left(\mathrm{X}_{4}\right)$ dan penggunaan pupuk $\left(\mathrm{X}_{5}\right)$. Sedangkan 2 faktor lainnya yaitu umur tanaman $\left(\mathrm{X}_{1}\right)$ dan jumlah hari sadap $\left(\mathrm{X}_{6}\right)$ tidak memiliki hubungan yang kuat. Berikut ini dijelaskan pengujian hipotesis dari masing-masing variabel bebas tersebut.

\section{Umur Tanaman $\left(\mathbf{X}_{1}\right)$}

Berdasarkan hasil regresi diperoleh nilai t hitung untuk variabel umur tanaman sebesar -0,172 dengan nilai probabilitas sigifikan sebesar 0,864 . Nilai $t$ hitung

Tabel 3. Hasil uji f pada model regresi

Table 3. F test results on the regression model

\begin{tabular}{llcrrrr}
\hline \multirow{2}{*}{ Model } & Sum of & Df & Mean Square & F & Sig. \\
& Squares & & & & \\
\hline 1 & Regression & $4,366 \mathrm{E} 11$ & 6 & $7,277 \mathrm{E} 10$ & $40,642^{* *}$ & ,000 \\
& Residual & $3,563 \mathrm{E} 11$ & 199 & $1,790 \mathrm{E} 9$ & & \\
& Total & $7,929 \mathrm{E} 11$ & 205 & & & \\
\hline
\end{tabular}

Tabel 4. Hubungan masing-masing variabel terhadap produksi karet petani Table 4. The relationship of each variable to the productions of rubber farmers

\begin{tabular}{lrrrr}
\hline \multicolumn{1}{c}{ Model } & $\begin{array}{c}\text { Standardized } \\
\text { Coefficients (B) }\end{array}$ & T & sig. & VIF \\
\hline C & &,- 371 &, 711 & \\
X $_{1}$ (Umur tanaman) &,- 008 &,- 172 &, 864 & 1,056 \\
X $_{2}$ (Kepemilikan lahan karet) & -412 & 5,463 &, 000 & 2,519 \\
X $_{3}$ (Tenaga kerja) &, 089 & 1,826 &, 069 & 1,048 \\
X $_{4}$ (Jenis bahan tanam yang digunakan) &,- 099 & $-1,725$ &, 086 & 1,461 \\
X $_{5}$ (Penggunaan pupuk) &, 390 & 4,883 &, 000 & 2,829 \\
X $_{6}$ (Jumlah hari sadap) &,- 009 &,- 196 &, 845 & 1,021 \\
\hline
\end{tabular}


sebesar $-0,172<\mathrm{t}$ tabel $(1,282)$, yang berarti bahwa variabel umur tanaman tidak berpengaruh nyata terhadap produksi karet di wilayah operasional perusahaan migas. Umur tanaman karet tidak berpengaruh terhadap produksi disebabkan kondisi ratarata umur tanaman karet yang ada dilokasi penelitian sudah lebih dari 26 tahun sehingga dengan kondisi tersebut tanaman karet kurang produktif atau sudah memasuki masa peremajaan sehingga potensi produksi sangat rendah. Pada umumnya potensi produksi karet akan lebih tinggi pada saat umur tanaman karet $15-23$ tahun (Nofriadi, 2016; Ulfah, et al., 2015). Selain itu menurut Budiman, (2012), umur tanaman menghasilkan pada tanaman karet adalah selama 25 tahun sadap dengan sifat produksi sebagai berikut :

a. Kelas Taruna bersifat belum potensial (612 tahun),

b. Kelas Muda bersifat potensial (13-18 tahun),

c. Kelas Dewasa bersifat sangat potensial (19-23 tahun),

d. Kelas Tua bersifat kurang potensial (2427 tahun),

e. Kelas Tua Rusak bersifat tidak potensial (> 27 tahun).

\section{Kepemilikan lahan karet $\left(\mathbf{X}_{2}\right)$}

Berdasarkan hasil regresi diperoleh nilai $\mathrm{t}$ hitung untuk variabel kepemilikan lahan karet sebesar 5,463 dengan nilai probabilitas sigifikan sebesar 0,000. Nilai t hitung sebesar $5,463>\mathrm{t}$ tabel $(1,282)$, artinya bahwa variabel kepemilikan lahan karet berpengaruh nyata terhadap produksi karet di wilayah operasional perusahaan migas. Hal tersebut sejalan dengan penelitian yang dilakukan oleh Simamora, Yusri, \& Dewi, (2017) yang menyatakan kepemilikan lahan karet berpengaruh nyata terhadap produksi karet. Semakin besar kepemilikan lahan karet akan berbanding lurus dengan produksi karet. kepemilikan lahan karet di lokasi penelitian tergolong luas, rata-rata luasan kepemilikan kebun mencapai 4,5 Ha per orang. Luasnya kepemilikan kebun karet di lokasi penelitian karena wilayah tersebut belum padat penduduk dan berkebun merupakan salah satu penghasilan keluarga petani.

\section{Tenaga Kerja $\left(\mathbf{X}_{3}\right)$}

Berdasarkan hasil regresi diperoleh nilai $t$ hitung untuk variabel tenaga kerja sebesar 1,826 dengan nilai probabilitas sigifikan sebesar 0,069. Nilai $t$ hitung sebesar $1,826>\mathrm{t}$ tabel $(1,282)$, artinya bahwa variabel tenaga kerja berpengaruh nyata terhadap produksi karet di wilayah operasional perusahaan migas. Hal ini sejalan dengan penelitian yang dilakukan oleh Pujianti \& Antara, (2016) yang menyatakan bahwa variabel tenaga kerja berpengaruh nyata terhadap produksi karet. Tenaga kerja yang digunakan oleh petani karet di wilayah operasional perusahaan migas sebesar $33 \mathrm{HOK}$ per bulan yang terdiri dari 18 HOK untuk kegiatan penyadapan karet dan 15 HOK digunakan untuk memelihara tanaman karet baik itu melakukan pemupukan maupun penyiangan gulma. Sehingga jika tenaga kerja meningkat akan meningkatkan produksi karet karena dengan penambahan tenaga kerja maka petani akan sering berada dikebun untuk memelihara kebun karet lebih baik lagi yang dapat meningkatkan produksi karet.

\section{Jenis bahan tanam yang digunakan $\left(\mathrm{X}_{4}\right)$}

Berdasarkan hasil regresi diperoleh nilai $t$ hitung untuk variabel jenis bahan tanam yang digunakan dengan nilai probabilitas sigifikan sebesar 0,086. Nilai signifikansi lebih kecil dari taraf nyata $10 \%$, artinya bahwa variabel jenis bahan tanam yang digunakan berpengaruh nyata terhadap produksi karet di wilayah operasional perusahaan migas. Pada umumnya petani yang berada diwilayah operasional perusahaan migas masih banyak yang menggunakan bibit seedling sehingga produksinya lebih rendah dibandingkan petani karet yang menggunakan bibit unggul. Petani yang sudah menggunakan bibit unggul untuk seluruh kebunnya sebesar $20 \%$ sedangkan petani yang masih menggunakan bibit seedling dan unggul sebesar $18 \%$ dan sisanya sebesar $62 \%$ petani masih menggunakan bibit seedling. Rendahnya tingkat adopsi klon unggul salah satunya disebabkan modal untuk mendapatkan bibit unggul dan sedikitnya penangkar bibit karet unggul di desa tersebut. 


\section{Penggunaan Pupuk $\left(\mathbf{X}_{5}\right)$}

Berdasarkan hasil regresi diperoleh nilai $t$ hitung untuk variabel penggunaan pupuk sebesar 4,883 dengan nilai probabilitas sigifikan sebesar 0,000. Nilai t hitung sebesar 4,883< t tabel $(1,282)$, artinya bahwa variabel pengunaan pupuk berpengaruh nyata terhadap produksi karet di wilayah operasional perusahaan migas. Secara umum tanaman karet yang kekurangan unsur hara akan menunjukkan tanaman kerdil, daun pucat, ukuran lilit batang lebih kecil dari ukuran standar serta periode tanaman belum menghasilkan akan lebih lama. Tanaman karet membutuhkan pupuk dengan tujuan mempertahankan kesuburan dan menjaga kelestarian tanah, menjaga keseimbangan hara tanah dan tanaman, mempercepat pertumbuhan tanaman, meningkatkan dan mempertahankan produksi serta meningkatkan ketahanan tanaman terhadap serangan penyakit (Wijaya \& Hidayati, 2012). Penelitian ini sejalan dengan yang dilakukan oleh Fitriani, Abidin, \& Ibnu, (2013) yang menyatakan bahwa variabel pupuk berpengaruh nyata terhadap produksi sehingga dapat meningkatkan produksi karet.

\section{Jumlah Hari Sadap $\left(\mathbf{X}_{6}\right)$}

Berdasarkan hasil regresi diperoleh nilai t hitung untuk variabel jumlah hari sadap sebesar -0,196 dengan nilai probabilitas sigifikan sebesar 0,845 . Nilai t hitung sebesar $-0,196<\mathrm{t}$ tabel $(1,282)$, yang berarti bahwa variabel jumlah hari sadap tidak berpengaruh nyata terhadap produksi karet di wilayah operasional perusahaan migas. Jumlah hari sadap yang dilakukan oleh petani karet rakyat rata-rata 6 hari dalam satu minggu, dengan kata lain hanya libur satu hari dalam seminggu. Tingginya jumlah hari sadap diharapkan oleh petani akan meningkatkan produksi karet petani. Namun hal tersebut tidak berdampak signifikan terhadap produksi. Berdasarkan penelitian yang dilakukan oleh Nugrahani, Rouf, Aji, Widyasari, \& Rinojati, (2017) menyatakan bahwa jumlah produksi per sadap dengan sistem d3 (sehari sadap, dua hari libur) lebih besar dibandingkan dengan setiap hari sadap. Tingginya jumlah hari sadap justru akan mempercepat habisnya bidang sadap karena setiap hari dilakukan penyadapan dan tanaman karet akan lebih cepat dilakukan peremajaan. Oleh karena itu untuk mendapatkan hasil yang optimal diperlukan sistem sadap yang sesuai dengan anjuran yaitu d3 (Kuswanhadi \& Herlinawati, 2012).

\section{Tingkat Pendapatan Petani Karet di Sekitar Wilayah Operasional Migas}

Tingkat kesejahteraan petani perlu diperhatikan agar keluarga petani karet dapat hidup layak. Kesejahteraan petani karet akan terwujud jika pendapatan keluarga dapat memenuhi kebutuhan keluarga baik itu sandang, papan dan pangan. Semakin tinggi pendapatan maka kebutuhan keluarga akan dapat terpenuhi. Sumber pendapatan petani karet di lokasi sekitar areal migas dapat dilihat pada Tabel 5.

Berdasarkan data diatas dapat dilihat bahwa pendapatan keluarga rata-rata mencapai IDR 3.732.000,- per bulan. Pendapatan karet merupakan sumber penghasilan keluarga terbesar sehingga komoditas karet sangat penting untuk peningkatan pendapatan keluarga. Pendapatan karet tersebut masih tergolong rendah karena petani karet masih bersifat

Tabel 5. Sumber pendapatan petani karet di sekitar operasional migas Table 5. S ource of income of rubber farmers around oil and gas operations

\begin{tabular}{clrr}
\hline No & & Sumber $p$ enerimaan & \multicolumn{2}{c}{ Total (IDR /bulan) } \\
No & & Sourcer of $p$ evenues & Total (IDR / month) \\
\hline 1 & Karet & 2.024 .000 \\
2 & Dagang & 629.000 \\
3 & Buruh & & 1.079 .000 \\
\hline \multicolumn{3}{c}{ Total } & 3.732 .000 \\
\hline
\end{tabular}

Sumber: Data Olahan, 2017

Source: Primer, 2017 
tradisional dalam membudidayakan karet baik itu penggunaan bahan tanam yang tidak unggul, pengolahan karet yang masih menggunakan pembeku tidak anjuran, penyimpanan karet yang masih direndam dan karet masih ada yang bercampur dengan kotoran. Selain itu juga pemasarannya yang masih tradisional mengakibatkan posisi tawar petani tidak kuat dan harga yang diterima tidak maksimal.

\section{KESIMPULAN}

Berdasarkan hasil studi dapat disimpulkan bahwa petani karet yang berada di wilayah operasional perusahaan migas sudah lama berkebun karet. Hal tersebut dilihat dari pengalaman petani berkebun karet rata-rata sudah mencapai 15 tahun, sehingga menjadikan kebun karet sebagai mata pencaharian utama yang berpengaruh pada perekonomian keluarga. Namun disisi lain tingkat pendidikan petani masih tergolong rendah yaitu $55 \%$ petani hanya mencapai jenjang pendidikan SD. Sedangkan faktor-faktor yang memiliki pengaruh nyata terhadap produksi karet adalah variabel kepemilikan lahan karet $\left(\mathrm{X}_{2}\right)$, tenaga kerja $\left(\mathrm{X}_{3}\right)$, jenis bahan tanam yang digunakan $\left(\mathrm{X}_{4}\right)$ dan penggunaan pupuk $\left(\mathrm{X}_{5}\right)$. Sedangkan variabel umur tanaman $\left(\mathrm{X}_{1}\right)$ dan jumlah hari sadap $\left(\mathrm{X}_{6}\right)$ tidak memiliki hubungan yang kuat terhadap peningkatan produksi karet. Sedangkan pendapatan keluarga sebesar IDR 3.732.000,- per bulan dan kegiatan usahatani karet merupakan kegiatan yang memberikan kontribusi terbesar kepada total pendapatan keluarga sebesar IDR 2.024.000,- per bulan (54\%), penghasilan dari berdagang sebesar IDR 629.000 ,- per bulan (17\%) serta sebagai buruh sebesar IDR 1.079.000,- per bulan $(29 \%)$.

Saran yang perlu diperhatikan adalah petani karet harus memperhatikan variabel yang dapat meningkatkan produksi karet seperti petani harus mengadopsi bibit karet unggul dan lebih rajin lagi dalam kegiatan pemeliharaan kebun serta memberikan pupuk dengan tepat dosis, tepat waktu, tepat sasaran.

\section{UCAPAN TERIMA KASIH}

Penulis mengucapkan terima kasih kepada Balai Penelitian Sembawa yang telah memfasilitasi selama kegiatan penelitian berlangsung, dan kepada Teknisi yang telah membantu dalam penginputan data penelitian.

\section{DAFTAR PUSTAKA}

Antariksa, Y. (2017). Peringkat 10 Besar Penyumbang Devisa Dollar ke Indonesia. Retrieved from http://strategimanajemen.net/2017/ $10 / 23 / \mathrm{ranking}-10-\mathrm{bes}$ ar penyumbang-devisa-dollar-keindonesia/

Boerhendhy, I. (2011). Perkembangan penggunaan bibit karet unggul di Sumatera Selatan. Warta Perkaretan, 30(2), 95-103.

Boerhendhy, I., \& Amypalupy, K. (2011). Optimalisasi produktivitas karet melalui penggunaan bahan tanam, pemeliharaan, sistem eksploitasi dan peremajaan tanaman. Jurnal Litbang, 30(1), 23-30.

Budiman, H. (2012). Budidaya Karet Unggul. Yogyakarta: Pustaka Baru Press.

Diantoro, K., Sunarsih, \& Soejono. (2009). Faktor-Faktor yang mempengaruhi produksi padi pada kelompok tani patemin kecamatan Tlogosari Kabupaten Bondowoso. Jurnal-SEP, 3(3), 55-60.

Direktorat Jenderal Perkebunan. (2016). Statistik Perkebunan Indonesia 20152017 Karet. Jakarta: Kementerian Perkebunan.

Firdaus, T., \& Huda, N. (2015). Analisis Faktor-Faktor yang mempengaruhi pendapatan petani karet di Kecamatan Singingi Kabupaten Kuantan Singingi Provinsi Riau. E-Jurnal Bung Hatta, 7(3), 1-15. 
Fitriani, E., Abidin, Z., \& Ibnu, M. (2013). Analisis produksi lateks pada PTPN VII Way Berulu. JIIA, 1(2), 105-110.

Hadi, H. (2010). Meningkatkan produktivitas berbasis mutu fisiologis bahan tanam. Majalah Hevea, 2(2), 42-44.

Hafsah, F. M., Violetta, \& C, P. (2014). Analisis Pendapatan dan Tingkat Kesejahteraan Petani Karet Perkebunan Plasma Desa Sungai Hijau Kecamatan Pangkalan Banteng Kabupaten Kotawaringin Barat Kalimantan Tengah. Institut Pertanian Bogor.

Harwati, W., Supardi, \& D, A. (2015). Faktor yang Mempengaruhi Pendapatan Petani Jagung (zea mays L) Studi Kasus di Desa Sidodadi Kecamatan Patean Kabupaten Kendal. Mediagro, 11(2), 77-86.

Kuswanhadi, \& Herlinawati, E. (2012). Saptabina Usahatani Karet Rakyat : Penyadapan. Sumatera Selatan: Balai Penelitian Sembawa.

LIPI. (2014a). Modul Diklat Jabatan Fungsional Peneliti Tingkat Pertama : Pengolahan dan Analisis Data. Cibinong: LIPI.

LIPI. (2014b). Modul Diklat Jabatan Fungsional Peneliti Tingkat Pertama : Teknis dan Praktik Pengumpulan Data Lapangan. Cibinong: LIPI.

Nazir, M. (2005). Metode Penelitan. Bogor: Ghalia Indonesia.

Nofriadi. (2016). Analisa faktor-faktor yang mempengaruhi produksi karet di Kecamatan Mestong Kabupaten Muaro Jambi Studi Kasus Desa Muari Sebapo. E- Jurnal Ekonomi Sumberdaya Dan Lingkungan, 5(1), 1-12.

Nugrahani, M. O., Rouf, A., Aji, Y., Widyasari, T., \& Rinojati, N. D. (2017). Kombinasi sistem sadap frekuensi rendah dan penggunaan stimulan untuk optimasi produksi dan penurunan biaya penyadapan di panel B0. Jurnal Penelitian Karet, 35(1), 59-70.
Pasaribu, M. H. (2017). Analisis FaktorFaktor yang Mempengaruhi Pendapatan Petani Karet di Desa Hasang Kabupaten Labuhan Batu Utara Sumatera Utara. Universitas Islam Negeri Sunan Kalijaga.

Pujianti, R., \& Antara, M. (2016). Analisis produksi karet rakyat di Desa Pontangoa Kecamatan Lembo Raya Kabupaten Morowali Utara. E-Jurnal Agrotekbis, 4(4), 485-490.

Sagala, A., Suhendry, I., \& Azwar, R. (1997). Produktivitas perkebunan karet dalam hubungannya dengan jenis klon dan agroklimat. Prosiding Apresiasi Teknologi Peningkatan Produktivitas Lahan Perkebunan Karet, 179-192.

Saptabina Usatani Karet Rakyat. (2012). Jakarta: Balai Penelitian Sembawa.

Septianita. (2009). Faktor-faktor yang mempengaruhi petani karet rakyat melakukan peremajaan karet di Kabupaten Ogan Komering ULU. Jurnal Agronobis, 1(1), 130-136.

Setyawan, E., Subantoro, R., \& Prabowo, R. (2016). Analisis faktor yang berpengaruh terhadap produksi karet di PT Perkebunan Nusantara IX Kebun Sukamangli Kabupaten Kendal. Mediagro, 12(1), 35-44.

Siburian, O. (2012). Analisis faktor-faktor yang mempengaruhi ekspor karet alam Indonesia ke Singapura tahun 1980-2010. Jurnal Analisis Pengembangan Ekonomi, 1(2), 1-6.

Simamora, D. I., Yusri, J., \& Dewi, N. (2017). Analisis faktor-faktor yang mempengaruhi produksi usahatani karet di Kecamatan Pangkalan Kuras Kabupaten Palelawan. Jurnal Online Mahasiswa Faperta Unsri, 4(2), 1-12.

Stiawan, A., Wahyuningsih, \& Nurjayanti. (2014). Faktor-faktor yang mempengaruhi pendapatan petani karet (Studi Kasus di Desa Getas Kecamatan Singorojo Kabupaten Kendal). Mediagro, 10(2), 69-80. 
Sudjarmoko, B., Listyuati, D., \& Hasibuan, A. M. (2013). Analisis faktor penentu adopsi benih unggul karet. Buletin Risri, 4(2), 117-128.

Sudrajat, M. (1985). Mengenal Ekonometrika Pemula. Bandung: Armico.

Syarifa, L. F., Agustina, D. S., Alamsyah, A., \& Nugraha, I. S. (2017). Dampak pola peremajaan partisipatif terhadap perkembangan perkebunan karet rakyat di Kabupaten Ogan Komering Ulu Provinsi Sumatera Selatan. Jurnal Penelitian Karet, 35(1), 71-82.
Syarifa, L. F., Agustina, D. S., Nancy, C., \& Supriadi. (2012). Evaluasi tingkat adopsi klon unggul di tingkat petani karet Provinsi Sumatera Selatan. Jurnal Penelitian Karet, 30(1), 12-22.

Ulfah, D., Thamrin, G., \& Natanael, T. (2015). Pengaruh waktu penyadapan dan umur tanaman karet terhadap produksi getah (lateks). Jurnal Hutan Tropis, 3(3), 247-252.

Wiajaya, T., \& Hidayati, U. (2012). Saptabina Usahatani Karet Rakyat: Pemupukan. Sumatera Selatan: Balai Penelitian Sembawa. 